\title{
Evaluation of In-vitro Antidiabetic and Hypolipidaemic Activities of Extracts Citrus Lemon Fruit
}

\author{
Abdelkader Basli ${ }^{1,2}$, Saida Younici ${ }^{2}$, Zahra Benkerrou $^{2}$, Bachra Khettal ${ }^{2}$ and Khodir Madani ${ }^{1}$ \\ 1. Research Laboratory of Biochemistry, Biophysics, Biomathematics and Scientometrics "L3BS", Faculty of Natural Sciences and \\ Life, University of Bejaia, Bejaia 06000, Algeria \\ 2. Plant Biotechnology Laboratory and Ethnobotany, Faculty of Natural Sciences and Life, University of Bejaia, Bejaia 06000, \\ Algeria
}

\begin{abstract}
Citrus genus is the most important fruit tree crop in the world and lemon is the third most important Citrus species. The evaluation of the potential inhibitory activity on $\alpha$-amylase and pancreatic lipase by Citrus lemon fruits of Algerian origin aiming for new applications of the fruits in nutrition and health was carried out. Lemon fruit EtOAc (ethyl acetate) extract showed higher contents of phytochemicals such as total phenolics and flavonoids. Furthermore, lemon fruit showed higher potential for inhibitory effects on $\alpha$-amylase and pancreatic lipase. It could be concluded that lemon fruits are of great value for nutrition and treatment of diet-related diseases such as obesity and diabetes.
\end{abstract}

Key words: Diabetes, flavonoids, obesity, polyphenols.

\section{Introduction}

Diabetes mellitus is a clinical syndrome characterized by inappropriate persistently elevated blood glucose concentration caused by deficiency of insulin at the cellular level, leading to acute or long term complications [1]. Globally, diabetes mellitus presents enormous and increasingly important public health issues. The prevalence of diabetes continues to rise and at the present, more than 220 million people worldwide have diabetes and the number of diabetes deaths will double in 2030 [2]. Currently, available therapies for diabetes include insulin and various oral antidiabetic agents such as sulfonylureas, biguanides and $\alpha$-glycosidase inhibitors. These agents, however, have restricted usage due to several undesirable side effects and fail to significantly after the course of diabetic complications [3]. Moreover, diabetes is associated with increased risk of thrombotic, atherosclerotic and cardiovascular disease [4]. It is well

Corresponding author: Abdelkader Basli, Ph.D., main research field: biochemistry. established that patients with diabetes type 2 frequently have abnormal serum lipid profile. The dyslipidemia is characterized by low levels of HDL (High-Density Lipoprotein)-cholesterol, and high levels of LDL (Low-Density Lipoprotein)-cholesterol and TGS (Triglycerides) [5, 6]. Studies have suggested that excessive intake of calories are related to chronic diseases, including type 2 diabetes mellitus, CVD (Cardiovascular Disease) and obesity. These are all linked to oxidative stress, causing an imbalance of pro oxidants and antioxidants in cellular systems, which impairs normal biological functions [7, 8].

Inhibition of $\alpha$-amylase, enzyme that plays a role in digestion of starch and glycogen, is considered a strategy for the treatment of disorders in carbohydrate uptake, such as diabetes and obesity. A wide array of numerous chemical compounds has demonstrated activity consistent with their possible use in the treatment of diabetes [9-12]. Different plants have been reported to show $\alpha$-amylase inhibitory activity and so may be relevant to the treatment of diabetes [13, 14]. The potential role of the medicinal plants as inhibitors 
of $\alpha$-amylase has been frequently assigned to phenolic compounds which possess various degrees of antioxidant or free radical scavenging properties as well as medicinal properties and have long been used as drugs [15-18]. Furthermore, flavonoids, abundant class of natural phenolic compounds showed that the potency of $\alpha$-amylase inhibition is correlated with the number of hydroxyl groups on the B ring of the flavonoid skeleton [19].

Citrus lemon is an important medicinal plant of the family Rutaceae and it is a very popular fruit all over the world due to the taste, aromatic flavor and healing properties [20, 21]. In Algeria, C. lemon is among the most popular fruits grown and it is an important source of photochemical such as vitamin c, phenolic compounds, many of which have potent antioxidant activities which are often exploited in food products and in various medicinal treatments [22, 23]. A significant fraction of flavonoids was found in $C$. lemon which includes hesperidin, quercitrin, eriocitrin, didymin and naringin [24]. The role of naringin has been reported for its antidiabetic effects [25]. C. lemon flavonoids have also shown having a broad spectrum of biological activity including antimicrobial, anticancer and antiviral activities [26-30].

The present investigation was undertaken to evaluate the in vitro inhibition activities antidiabetic and hypolipidemic using $\alpha$-amylase and pancreatic lipase of EtOAc extract fruit of C. lemon.

\section{Material and Methods}

\subsection{Material}

Fresh fruit used in this study were obtained on the local market at city Bejaia, Algeria, 2014. Fresh fruits were washed in tap water running in the laboratory, rinsed with sterile distilled water. The pressed juice was put into a vessel separately, and then the fruits were cut with a sterile knife, dried in dry and powdered.

\subsection{Extraction}

Five grams of fruit $C$. lemon powder were extracted for $12 \mathrm{~h}$ with $200 \mathrm{~mL}$ of $70 \%$ hydro-alcoholic solvent (methanol/water) at room temperature. The extract was filtered, and then the residue was extracted for the second time with $100 \mathrm{~mL}$ of the same hydro-alcoholic solvent for $12 \mathrm{~h}$ at room temperature. After removal of methanol under reduced pressure in a rotary evaporator at $40{ }^{\circ} \mathrm{C}$, the remaining aqueous solution of the extraction was defatted twice with petroleum ether to remove lipids. Then, the aqueous fraction was extracted with ethyl acetate. The organic fractions evaporated to dryness using a rotary evaporator. The dried residue was dissolved in of methanol and kept at $4{ }^{\circ} \mathrm{C}$.

\subsection{Determination of Total Phenolic Compound}

The amount of total phenolic in the sample was determined with the Folin-Ciocalteu reagent using the method of Singleton and Ross (1965) [31]. $100 \mu \mathrm{L}$ of EtOAc lemon extract was added to $500 \mu \mathrm{L}$ of the aqueous solution of Folin-Ciocalteu reagent at $10 \%$. After $2 \mathrm{~min}$ incubation at room temperature, $2 \mathrm{~mL}$ of $2 \%(\mathrm{w} / \mathrm{v})$ sodium carbonate in water were added. Blank was prepared by replacing the reagent by water to correct for interfering compound. After $30 \mathrm{~min}$ of incubation in the dark at room temperature, the absorbance was measured at $760 \mathrm{~nm}$ using the Shimadzu 1601 visible spectrophotometer. The gallic acid was used as a standard and the results were expressed as milligram of GAE (Gallic Acid Equivalents) per gram dry extract. The entire assay was carried out at least in triplicate.

\subsection{Determination of Total Flavonoids}

Total flavonoids content in the citrus fruit extract was determined spectrophotometrically using a method based on the formation of a flavonoid-aluminium complex with an absorbance maximum at $430 \mathrm{~nm}$ [32]. The examined extract $(1 \mathrm{~mL})$ was mixed with $2 \%$ $\mathrm{AlCl}_{3} \times 6 \mathrm{H}_{2} \mathrm{O}(0.5 \mathrm{~mL})$. After incubation at room temperature for $30 \mathrm{~min}$, the absorbance of the reaction mixtures was measured. The blank sample was a 1:1 
mixture of the examined extract and distilled water. Flavonoids content was expressed in $\mu \mathrm{g}$ quercetin equivalent per gram dried extract by using a standard curve of quercetin (concentration range 0.5-6.0 $\mu \mathrm{g} / \mathrm{mL}$ ). All measurements were replicated for three times.

\subsection{In vitro $\alpha$-amylase Inhibitory Activity}

This study was performed by a modified starch iodine protocol [33]. In short, $80 \mu \mathrm{L}$ of EtOAc lemon extract or standard (acarbose) of different concentration was taken in pre-labeled test tubes. A volume of $20 \mu \mathrm{L}$ of $\alpha$-amylase was added to each test tube and incubated for $10 \mathrm{~min}$ at $37{ }^{\circ} \mathrm{C}$. After the incubation $200 \mu \mathrm{L}$ of $1 \%$ starch solution was added to each test tube and the mixture was re-incubated for $1 \mathrm{~h}$ at $37^{\circ} \mathrm{C}$. Then $200 \mu \mathrm{L}$ of $1 \%$ iodine solution was added to each test tube and after that, $10 \mathrm{~mL}$ distilled water was added. Absorbance of the mixture was taken at 565 $\mathrm{nm}$. The experiments were repeated thrice and the percentage inhibition was calculated by the expression:

$$
\% \text { inhibition }=\frac{\text { Absorbance Control-Absorbance Test }}{\text { Absorbance Control }} \times
$$$$
100
$$

\subsection{Lipase Inhibitory Activity}

Inhibition of lipase by the EtOAc lemon extract was determined using a modified assay [34]. Briefly, a suspension containing $1 \%(\mathrm{v} / \mathrm{v})$ of triolein, and $1 \%(\mathrm{v} / \mathrm{v})$ Tween 40 in $0.1 \mathrm{M}$ phosphate buffer (pH 8) was prepared and emulsified. Assays were then initiated by adding $800 \mu \mathrm{L}$ of the triolein emulsion to $200 \mu \mathrm{L}$ of pancreatic lipase and $200 \mu \mathrm{L}$ of extract (or $0.1 \mathrm{M}$ Phosphate buffer, $\mathrm{pH} 8$ ). The contents were mixed and the absorbance measured immediately at $450 \mathrm{~nm}$ and designated as $T_{0}$. The test tubes were incubated at $37{ }^{\circ} \mathrm{C}$ for $30 \mathrm{~min}$ and at the end of the incubation; the absorbance at $450 \mathrm{~nm}$ was recorded and designated as $\mathrm{T}_{30}$.

The variation in absorbance $=\left[\mathrm{A}_{450}\left(\mathrm{~T}_{0}\right)-\mathrm{A}_{450}\left(\mathrm{~T}_{30}\right)\right]$ was calculated for both control and the test and the $\%$ inhibition was calculated using the formula:

$$
\begin{aligned}
\% \text { inhibition }= & \frac{\left(\Delta A_{450} \text { control }-\Delta A_{450} \text { Extract }\right)}{\left(\Delta A_{450} \text { control }\right)} \\
& \times 100
\end{aligned}
$$

\section{Results and Discussions}

\subsection{Polyphenols and Flavonoids Content}

Analysis of Folin-Ciocalteu index is one of the oldest methods developed to determine the content of total phenols. The average values of total phenols ranged from $63.9 \pm 0.16 \mathrm{mg} \mathrm{GAE} / \mathrm{g}$ and $12.3 \pm 0.30 \mathrm{mg}$ of flavonoids $\mathrm{QE} / \mathrm{g}$. These results agree with other studies which have shown that lemon was found to contain the highest total phenolic and flavonoids contents [35-39]. Some authors have even reported that the total polyphenol content in the peeled lemons and their peels are significantly higher than those in oranges and grapefruits, peeled and peels, respectively [38]. In addition, total phenolics and total flavonoid content were still significantly higher in the skin than those in the pulp for all citrus fruits, in accordance with previous studies [40, 41]. Therefore, citrus peels have been widely studied because they contain many biologically active compounds, including natural antioxidants such as phenolic acids and flavonoids [42, 43]. Flavonoids are the most abundant phenolic compounds present in Citrus fruits. The content of flavonoids in peels is 10-time greater than the content of the juice. Among them, flavanone glycosides predominate, together with other low amount flavonoids such as methoxylated flavones, flavones glycosides and anthocyanins [44, 45]. Then, the consumption of fruit and citrus juice has been widely studied for its possible role in promoting health and preventing human disease. These beneficial effects are mainly due to flavanones, polyphenols typical citrus species [46-48].

\subsection{Inhibition of $\alpha$-Amylase Activity}

Extract EtOAc showed a potent inhibition of $\alpha$-amylase enzyme. In fact, the IC50 values of Citrus 
lemon fruit extract and standard acarbose against $\alpha$-amylase were $103.46 \mu \mathrm{g} / \mathrm{mL}$ and $134.17 \mu \mathrm{g} / \mathrm{mL}$, respectively. Lemon extract significantly inhibited $\alpha$-amylase activity in a dose dependent manner likeacarbose. The result of in vitro $\alpha$-amylase inhibitory activity of lemon fruits extract was shown in Table 1.

The potent $\alpha$-amylase inhibitory activity of the EtOAc lemon extract depended on amount of total phenolic and flavonoids in extract. Recent studies have shown that phenolic phytochemicals exert anti-diabetic effect through inhibition of carbohydrate-hydrolyzing enzymes, such as alpha-amylase. In fact, many phenolic compounds and specially flavonoids have been reported as potential antidiabetic agents because they exert a good inhibitory action against $\alpha$-amylase and could have potential prevention in diabetes mellitus as part of a dietary strategy [49]. These results were confirmed by others studies which showed that all of the tested Citrus flavonoids significantly inhibited amylase-catalyzed starch digestion [50]. Natural alpha-amylase inhibitors offer an attractive approach to the management of postprandial hyperglycemia by decreasing glucose release from starch [51]. Moreover, several findings suggest that phenolic synergies may play a role in mediating amylase inhibition and therefore have the potential to contribute to the management of type 2 diabetes [52].

\subsection{Pancreatic Lipase in vitro Assay}

The EtAOc lemon extract as well as Orlistat, a pancreatic lipase inhibitor used as an anti-obesity agent exhibited a strong inhibition pancreatic lipase in vitro activity. They inhibited the enzyme activity with $\mathrm{IC}_{50}$ corresponding to 110.07 and $98.40 \mu \mathrm{g} / \mathrm{mL}$, respectively. The inhibition activity of lemon extract and Orlistat against pancreatic lipase was significantly similar and shown in dose-dependent manner. The inhibitory activity towards pancreatic lipase was reported in Table 2.

Obesity is found to be strong risk factor for type 2 diabetes. Dietary lipids represent the major source of unwanted calories; therefore, lipid metabolism is a vital and subtle balance that maintains energy homeostasis. A vast range of health problems co-exist with a weight problem and dysfunction of lipid homeostasis.

Table 1 In vitro $\alpha$-amylase inhibitory activity for $C$. lemon EtOAc fruit extract and acarbose.

\begin{tabular}{llll}
\hline Sample & Concent $(\mu \mathrm{g} / \mathrm{mL})$ & \%Inhibition & $\mathrm{IC}_{50} \mu \mathrm{g} / \mathrm{mL}$ \\
\hline \multirow{3}{*}{ Acarbose } & 50 & $31.53 \pm 0.14$ & \\
& 150 & $72.49 \pm 0.09$ & \\
& 300 & $82.92 \pm 0.12$ & \\
EtOAc & 50 & $38.02 \pm 0.1$ & 134.17 \\
& 150 & $55.9 \pm 0.11$ & \\
\hline
\end{tabular}

Values are the mean of triplicate experiments and represented as mean $\pm \operatorname{SEM}(n=3)$.

Table 2 In vitro lipase inhibitory activity of EtOAc fruit lemon extract.

\begin{tabular}{llll}
\hline Sample & Concent $(\mu \mathrm{g} / \mathrm{mL})$ & \%inhibition & $\mathrm{IC}_{50} \mu \mathrm{g} / \mathrm{mL}$ \\
\hline \multirow{3}{*}{ Orlistat } & 25 & $21.09 \pm 0.1$ & \\
& 100 & $32.15 \pm 0.05$ & 98.40 \\
& 125 & $63.52 \pm 0.02$ & \\
250 & $86.33 \pm 0.9$ & 110.07 \\
EtOAc & 25 & $21.50 \pm 0.1$ & \\
& 100 & $45.63 \pm 0.01$ & \\
& 125 & $56.78 \pm 0.15$ & \\
\hline
\end{tabular}

Values are the mean of triplicate experiments and represented as mean $\pm \operatorname{SEM}(n=3)$. 
Pancreatic lipase is the key enzyme for dietary fat digestion [53], and inhibition of the enzyme could be an effective way to alter fat absorption. In fact, Orlistat, an appetite suppressor, is the main anti-obesity medications currently approved [54]. However, because Orlistat can result in undesirable side effects, such as fecal incontinence, flatulence and steatorrhea, its use may be limited [55]. It may be worthwhile to search the natural substances that show potent inhibitory activity. So far, many natural products (plant extracts and isolated compounds) have been reported for their pancreatic lipase inhibition property. It has been shown that Citrus fruits inhibited pancreatic lipase activity dose dependently and are of great value for nutrition and treatment of diet-related diseases such as obesity and diabetes [56]. The lipase inhibitory effect observed on Citrus $s p$. such as lemon could be due to the acidic plant extracts which having $\mathrm{pH}$ values below 4.0 [57].

\section{Conclusion}

It can be concluded that fruit of Citrus lemon can be promising an antidiabetic and hypolipidaemic. This verifies the traditional use of this plant as hypoglycaemic agents. Ideally, such research will lead to a more effective and safer pharmacological treatment of diabetes and obesity.

\section{References}

[1] Haire Joshu, D. 1991. Management of Diabetes Mellitus: Perspective of Care across the Life Span, edited by St. Louis, Mo., Mosby. 190-214.

[2] Fonseca, V. A. 2006. Clinical Diabetes: Translating Research into Practice. Philadelphia: Saunders Elsevier. 2-3.

[3] Chandramohan, G., Ignacimuthu, S., and Pugalendi, K. V. A. 2008. "Novel Compound from Caseariaesculenta (Roxb) Root and its Effect on Carbohydrate Metabolism in Streptozotocin-Diabetic Rats." European Journal of Pharmacology 590 (1-3): 437-43.

[4] Grover, J. K., Yadav, S., and Vats, V. 2002. "Medicinal Plants of India with Anti-diabetic Potential." Journal of Ethnopharmacology 81 (1): 81-100.

[5] Raida, K., Nizar, A., and Barakat, S. 2008. "The Effect of
Crataegusaronica Aqueous Extract in Rabbits Fed with High Cholesterol Diet." European Journal of Scientific Research 22 (3): 352-60.

[6] Park, J. B., and Velasquez, M. T. 2012. "Potential Effects of Lignan-enriched Flaxseed Powder on Bodyweight, Visceral Fat, Lipid Profile and Blood Pressure in Rats." Fitoterapia 83 (5): 941-6.

[7] Droge, W. 2002. "Free Radicals in the Physiological Control of Cell Function." Physiological Reviews 82 (1): 47-95.

[8] Hossain, S. J., El-Sayed, M. A., Mohamed A. H., Shehed, M. G., and Aoshima, H. 2009. "Phenolic Content, Anti-oxidative, Anti- $\alpha$-amylase and Anti- $\alpha$-glucosidase Activities of Solanum Diphyllum L.." Bangladesh Journal of Botany 38 (2): 139-43.

[9] Kandra, L. 2003. " $\alpha$-Amylases of Medical and Industrial Importance." Journal of Molecular Structure 666: 487-98.

[10] Brayer, G. D., Luo, Y., and Withers, S. G. 1995. "The Structure of Human Pancreatic $\alpha$-amylase at $1.8 \mathrm{~A}$ Resolution and Comparisons with Related Enzymes." Protein Science 4 (9): 1730-42.

[11] Tangphatsornruang, S., Naconsie, M., Thammarongtham, C., and Narangajavana J. 2005. "Isolation and Characterization of an $\alpha$-Amylase Gene in Cassava (Manihotesculenta)." Plant Physiology and Biochemistry 43 (9): 821-7.

[12] Iulek, J., Franco, O. L., Silva, M., Slivinski, C. T., Bloch, C., Rigden, D. J., et al. 2000. "Purification, Biochemical Characterisation and Partial Primary Structure of a New $\alpha$-Amylase Inhibitor from Secalecereale (rye)." International Journal of Biochemistry \& Cell Biology 32 (11): 1195-204.

[13] Mentreddy, S. R. 2007. "Medicinal Plant Species with Potential Antidiabetic Properties." Journal of the Science of Food and Agriculture 87 (5): 743-50.

[14] Sales, P. M., Souza, P. M., Simeoni, L. A., and Silveira, D. 2012. " $\alpha$-Amylase Inhibitors: a Review of Raw Material and Isolated Compounds from Plant Source." Journal of Pharmacyand Pharmaceutical Sciences 15 (1): 141-83.

[15] McDougall, D., Shpiro, G. J., Dobson, F., Smith, P., Blake, P., and Stewart, A. 2005. "Different Polyphenolic Components of Soft Fruits Inhibit $\alpha$-Amylase and a-Glucosidase." Journal of Agricultural and Food Chemistry 53 (7): 2760-6.

[16] Reddy, N. V. L. S., Anarthe, S. J., and Raghavendra, N. M. 2010. "Effect of Thermal Treatment and Phenolic Content." Journal of Biomedical Science 1 (2): 72-5.

[17] Ramkumar, K. M., Thayumanavan, B., Palvannan, T., and Rajaguru, P. 2010. "Inhibitory Effect of Gymnemamontanum Leaves on $\alpha$-glucosidase Activity 
and $\alpha$-Amylase Activity and Their Relationship with Polyphenolic Content." Medicinal Chemistry Research 19 (8): 948-61.

[18] Gaurav, P., Gaurav, K., Karthik, L., Prasuna, G., Bhaskara, R., and Rao, K. V. 2011. "Antioxidant Activity of Methanolic Extract of Blue Green Algae Anabaena sp. (Nostocaceae)." European Journal of Experimental Biology 1 (1): 156-62.

[19] Lo Piparo, E., Scheib, H., Frei, N., Williamson, G., Grigorov, M., and Chou, C. J. 2008. "Flavonoids for Controlling Starch Digestion: Structural Requirements for Inhibiting Human $\alpha$-Amylase." Journal of Medicinal Chemistry 51 (12): 3555-61.

[20] Ali, S., and Mirza, B. 2006. Micropropagation of Rough Lemon (Citrus jambhiri Lush.): Effect of Explants Type and Hormone Concentration." Acta Botanica Croatica 65 (2): $137-46$.

[21] Gaurav, K., and Richa, S. 2012. "In Vitro Micro Propagation of Different Species of Citrus." Research Journal of Biotechnology 7 (4): 96-101.

[22] Di Majo, D., Giammanco, M., La Guardia, M., Tripoli, E., Giammanco, S., and Finotti, E. 2005. "Flavanones in Citrus Fruit: Structure-Antioxidant Activity Relationships." Food Research International 38 (10): 1161-6.

[23] Jayaprakasha, G. K., and Patil, B. S. 2007. "In Vitro Evaluation of the Antioxidant Activities in Fruit Extracts from Citron and Blood Orange." Food Chemistry 101 (1): 410-8.

[24] Nijveldt, R. N. V., Hoorn, D. E. C. V., Boelens, P. G., Norren, K. V., and Leeuwen, P. A. V. 2001. "Flavonoids: a Review of Probable Mechanisms of Action and Potential Applications." American Journal of Clinical Nutrition 74 (4): 418-25.

[25] Pari, L., and Suman, S. 2010. "Antihyperglycemic and Antilipidperoxidative Effect of Flavonoid Naringin in Streptozotocin-Nictonamide Induced Diabetic Rats." International Journal of Biological and Medical Research 1: 206-10.

[26] Dhanavada, M. J., Jalkute, C. B., Ghosh, J. S., and Sonawane, K. D. 2011. "Study Antimicrobial Activity of Lemon (Citrus lemon) Peel Extract." British Journal of Pharmacology and Toxicology 2 (3): 119-22.

[27] Pandey, A., Kaushik, A., and Tiwari, S. K. 2011. "Evaluation of Antimicrobial Activity \& Phytochemical Analysis Citrus lemon." Journal of Pharmaceutical and Biomedical Sciences 13 (17): 1-7.

[28] Tanaka, T., Makita, H., Kawabata, K., Mori, H., Kakumoto, M., Satoh, K., et al. 1997. "Chemoprevention of Azoxymethane-Induced Rat Colon Carcinogenesis by Naturally Occurring Flavonoids, Diosmin and Hesperidin." Carcinogenesis 18 (5): 957-65.
[29] Galati, M., Monforte, M. T., Kirjavainen, S., Forestieri, A. M., Trovato, A., and Tripodo, M. M. 1994. "Biological Effects of Hesperidin, a Citrus Flavonoid (note I): Anti-inflammatory and Analgesic Activity." Farmaco 40 (11): 709-12.

[30] Kaul, T. N., Middleton, E., and Ogra, P. L. 1985. "Antiviral Effects of Flavonoids on Human Viruses." Journal of Medical Virology 15 (1): 71-9.

[31] Singleton, V. L, and Rossi, J. R. 1965. "Colorimetry of Total Phenolics with Phosphomolibdicphosphothungstic Acid." American Journal of Enology and Viticulture 16 (3): 144-58.

[32] Zhishen, J., Mengcheng, T., and Jianming, W. 1999. "The Determination of Flavonoid Contents in Mulberry and their Scavenging Effects on Superoxide Radicals." Food Chemistry 64 (4): 555-9.

[33] Hossan, S. J., El-Sayed, M., and Aoshima, H. 2009. "Antioxidative and Anti $\alpha$-amylase Activities of Four Wild Plants Consumed by Nomads in Egypt." Oriental Pharmacy and Experimental Medicine 9 (3): 217-24.

[34] Smeltzer, M. S., Hart, M. E., and Iandolo, J. J. 1992. "Quantitative Spectrophotometric Assay for Staphylococcal Lipase." Applied and Environmental Microbiology 58 (9): 2815-19.

[35] Bocco, A., Cuvelier, M. E., Richard, R., and Berset, C. 1998. "Antioxidant Activity and Phenolic Composition of Citrus Peel and Seed Extracts." Journal of Agricultural and Food Chemistry 46 (6): 2123-9.

[36] Wang, Y. C., Chuang, Y. C., and Hsu, H. W. 2008. "The Flavonoid, Carotenoid and Pectin Content in Peels of Citrus Cultivated in Taiwan." Food Chemistry 106 (1): 277-84.

[37] González-Molina, E. D. A., Moreno, R. D. A., and García- Viguera, C. 2010. "Natural Bioactive Compounds of Citrus limon for Food and Health." Journal of Pharmaceutical and Biomedical Analysis 51 (2): 327-45.

[38] Gorinstein, S., Martı'n-Belloso, O., Park, Y. S, Haruenkit, R., Lojek, A., Ciz, M., et al. 2001. "Comparison of Some Biochemical Characteristics of Different Citrus Fruits." Food Chemistry 74 (3): 309-15.

[39] Wu, T., Luo, J., and Xu, B. 2015. "In vitro Antidiabetic Effects of Selected Fruits and Vegetables against Glycosidase and Aldose Reductase." Food Science and Nutrition 3 (6): 495-505.

[40] Gorinstein, S., Zachwieja, Z., Katrich, E., Pawelzik, E., Haruenkit, R., and Trakhtenberg, S. 2004. "Comparison of the Contents of the Main Antioxidant Compounds and the Antioxidant Activity of White Grapefruit and his New Hybrid." Lebensmittel-Wissenschaft und-Technologie 37 (3): 337-43.

[41] Guimarães, R., Barros, L., Barreira, J. C., Sousa, M. J., Carvalho, A. M., and Ferreira, I. C. 2010. "Targeting 
Excessive Free Radicals with Peels and Juices of Citrus Fruits: Grapefruit, Lemon, Lime and Orange." Food and Chemical Toxicology 48 (1): 99-106.

[42] Bocco, A., Cuvelier, M. E., Richard, H., and Berset, C. 1998. "Antioxidant Activity and Phenolic Composition of Citrus Peel and Seed Extracts." Journal of Agricultural and Food Chemistry 46 (6): 2123-9.

[43] Horowitz, R. M. 1961. The Citrus Flavonoids. In The orange. Its Biochemistry and Physiology, edited by Senclair, W. B. California: University of California, 334-72.

[44] Dugo, G., and Di Giacomo, A. 2002. Citrus: the Genus Citrus, New York: Taylor \& Francis Group, CRC Press.

[45] Giannuzzo, A. N., Boggetti, H. J., Nazareno, M. A., and Mishima, H. T. 2003. "Supercritical Fluid Extraction of Naringin from the Peel of Citrus Paradis." Phytochemical Analysis 14 (4): 221-3.

[46] Mertz, C., Gancel, A. L., Gunata, Z., Alte, r P., Dhuique-Mayer, C., Vaillant, F., et al. 2009. "Phenolic Compounds, Carotenoids and Antioxidant Activity of Three Tropical Fruits." Journal of Food Composition and Analysis 22 (5): 381-7.

[47] Sun, H., Dong, T., Zhang, A., Yang, J., Yan, G., Sakurai, T., et al. 2013. "Pharmacokinetics of Hesperetin and Naringenin in the Zhi Zhu Wan, Traditional Chinese Medicinal Formulae and its Pharmacodynamics Study." Phytotherapy Research 27 (9): 1345-51.

[48] Khan, M. K., E-Huma, Z., and Dangles, O. 2014. "A Comprehensive Review on Flavanones, the Major Citrus Polyphenols." Journal of Food Composition and Analysis 33 (1): 85-104.

[49] Cazarolli, L. H., Zanatta, L., Alberton, E. H., Figueiredo, M. S, Folador, P., Damazio, R. G., et al. 2008.
"Flavonoids: Prospective Drug Candidates." Mini-Reviews in Medicinal Chemistry 8 (13): 1429-40.

[50] Shen, W., Xu, Y., and Lu, Y. H. 2012. "Inhibitory Effects of Citrus Flavonoids on Starch Digestion and Antihyperglycemic Effects in HepG2 Cells." Journal of Agricultural and Food Chemistry 60 (38): 9609-19.

[51] Kim, Y., Jeong, Y., Wang, M., Lee, W., and Rhee, H. 2005. "Inhibitory Effect of Pine Extracts on $\alpha$-Glucosidase Activity and Postprandial Hyperglycemia." Nutrition 21 (6): 756-61.

[52] Kwon, Y., Vattem, D., and Shetty, K. 2006. "Clonal Herbs of Laminaceae Species against Diabetes and Hypertension." Asia Pacific Journal of Clinical Nutrition 15 (1): 107-18.

[53] Olshansky, S. J., Passaro, D. J., Hershow, R. C., Layden, J., Carnes, B. A., Brody, J., et al. 2005. "A Potential Decline in Life Expectancy in the United States in the 21st Century." New England Journal of Medicine 352 (11): 1135-7.

[54] Jandacek, R. J., and Woods, S. C. 2004. "Pharmaceutical Approaches to the Treatment of Obesity." Drug Discovery Today 15 (20): 874-80.

[55] Birari, R. B., and Bhutani, K. K. 2007. "Pancreatic Lipase Inhibitors from Natural Sources: Unexplored Potential." Drug Discovery Today 12 (19): 879-89.

[56] Gironés Vilaplana, A., Moreno, D. A., and García Viguera, C. 2014. "Phytochemistry and Biological Activity of Spanish Citrus Fruits." Food \& Function 5 (4): 764-72.

[57] Danış, O., Ogan, A., Anbar, D., Dursun, B. Y., Demir, S., and Salan, U. 2015. "Inhibition of Pancreatic Lipase by Culinary Plant Extracts.” International Journal of Plant Biology \& Research 3 (2): 1038-41. 